\title{
Parental Bonding and Academic Burnout on Addiction Potential
} Among Students

\author{
Abbas Ziari, ${ }^{1}$ Majid Mirmohammadkhani, ${ }^{1}$ Mohammad Amin Vafaei, ${ }^{2}$ Mohammadreza Moonesan, ${ }^{3}$ \\ Mojtaba Soltani, ${ }^{4}$ and Masoudeh Babakhanian ${ }^{5,6,}{ }^{*}$ \\ ${ }^{1}$ Social Determinants of Health Research Center, Semnan University of Medical Sciences, Semnan, Iran \\ ${ }^{2}$ Student Research Committee, Semnan University of Medical Sciences, Semnan, Iran \\ ${ }^{3}$ Department of Emergency Medicine, Semnan University of Medical Sciences, Semnan, Iran \\ ${ }^{4}$ Faculty of Education and Psychology, University of Isfahan, Isfahan, Iran \\ ${ }^{5}$ Social determinants of health Research center, Semnan University of Medical Sciences, Semnan,Iran \\ ${ }^{6}$ Psychiatry and Behavioral Sciences Research Center, Mazandaran University of Medical Sciences, Sari, Mazandaran, Iran \\ "Correspond author: Masoudeh Babakhanian, Social Determinants of Health Research Center, Semnan University of Medical Sciences, Semnan, Iran. Tel/Fax: +98-2335225141, \\ E-mail: babakhanian.m@gmail.com
}

Received 2017 April 30; Revised 2017 May 16; Accepted 2017 June 25.

\begin{abstract}
Background: The risk of drug abuse during youth and adolescence depends on the individual's family structure. Parents' interaction methods and parenting styles are an important part of the social context. Since the interaction between parents and children has a great influence on students' addiction, this study was conducted to assess the relationship between parental bonding and academic burnout with addiction potential among students studying in Semnan University of Medical Sciences.

Methods: This study was a cross sectional descriptive analytical study conducted on 245 students studying in Semnan University of Medical Sciences (2014 - 2015) using the valid Pierson's questionnaire about parental bonding, school burnout, and addiction potential. The scores of addiction potential, school-burnout, and parental child bonding were obtained. The correlation and multiple regression models were then investigated.

Results: The scores of addiction potential and academic burnout were $79.03 \pm 13.26$ and $32.02 \pm 15.84$, respectively. In fact, in the reduced multiple regression model only male gender $(b=6.718, P<0.001)$, higher grade point average $(b=3.556, P=0.020)$, higher school-burnout $(b=6.460, P<0.001)$, higher care by parents (father's care, $b=6.503, P<0.001$, mother's care $(b=6.336, P=0.001)$, and less control by the father $(\mathrm{b}=-4.058, \mathrm{P}=0.007)$ were associated with increased susceptibility of students to addiction.

Conclusions: Numerous factors, such as male gender, higher grade point average, greater school burnout and care by both parents and less control by the father were associated with increased susceptibility of students to addiction and they provided the conditions for addiction among students.
\end{abstract}

Keywords: Parental Bonding, Academic Burnout, Addiction Potential, University Students

\section{Background}

Drug dependence is currently one of the most significant problems and concerns around the world (1). Drug abuse is observed in all social levels (2). Much progress has been made in the world in understanding the reasons for the prevalence of drug abuse. Addiction potential is an inner state, in which a person has a high level of willingness for addiction $(3,4)$.

Given the structure of the young population in Iran, various factors, such as individual, interpersonal, and social factors are involved in young people's tendency towards addiction. Because of the high prevalence of drug dependence and its treatment difficulties, it is of great importance to make efforts to identify the risk factors for this problem among the youth population, especially students of medicine and medical allied sciences, who have easier access to various drugs (5).

On the other hand, in youth and adolescence, the risk of drug abuse depends on the individual's family structure $(6,7)$. Studies have shown that parents' interaction methods and parenting style are the most important part of the social context, in which the adolescent experiences his/her own personal growth. Benjet et al. (2014) conducted a study with the aim of evaluating the relationship between chronic troubles and different stages of drug addiction; the results showed that childhood troubles were associated with opportunities for alcohol consumption and illegal chances for drug abuse. Lamborn et al. (1991) conducted a study to determine the effectiveness of parenting styles on drug abuse by teenagers; the results showed that the probability of alcohol consumption in families with authoritarian parents was less than peers with indulgent 
parents. In fact, the adolescents living with indulgent families were more likely to use drugs and alcohol, and they also had poor academic achievement $(8,9)$.

Accordingly, the interaction between parents and children could have a great influence on students' addiction vulnerability; on the other hand, the specific circumstances and particular difficulties of curriculums at universities of medical sciences make the medical and paramedical students different from other students, and this is considered as the underlying cause of this problem. Due to the relative shortage of similar studies among the students of universities of medical sciences, this study was conducted in Semnan University of Medical Sciences, during year 2015.

\section{Objectives}

Since the interaction between parents and children has a great influence on students' addiction, this study was conducted to assess the relationship between parental bonding, academic-burnout, and addiction potential among students of Semnan University of Medical Sciences.

\section{Methods}

This cross sectional and descriptive analytical study was approved by the Ethical Committee of Semnan University of Medical Sciences and was conducted on male and female university students (2014 to 2015). The subjects were selected via simple random sampling among students of medical, nursing, paramedical, and rehabilitation faculties of Semnan University of Medical Sciences. The samples were selected randomly from lists of students' names using random numbers of excel software to participate in this study. The sample size was calculated as 300 cases using Cochran's formula for a finite population with a maximum of $20 \%$ for non-response.

Before completing the questionnaire, the objectives of the study were explained to the participants before obtaining there written consent. They were assured about the confidentiality of their information and they were also assured that after analyzing the data, the questionnaires would be destroyed.

Instrument: In this study, to collect the required data in addition to a demographic questionnaire, three standard tools were used; including addiction potential, academic-burnout, and parental bonding inventories. The addiction potential scale was developed by Weed Butcher (1992) (10) and some efforts were made to determine its validity in Iran (11).
The questionnaire is the Persian version of addiction potential scale, developed by Zargar (2006), adapted to the psychological and the social conditions of Iranian people. The questionnaire consists of 2 factors with 36 main items and 5 lie detector items.

Each question is scored on a continuum from 0 (strongly disagree) to 3 (strongly agree). In order to calculate the overall score of the responses to the questions, the points obtained for every single question except the lie-detector items were summed up. Higher scores indicate higher addiction potential for the individual and vice versa. This questionnaire contains 2 factors, active potential and passive one. Active potential is related to antisocial behaviors, tendency towards drug abuse, positive attitude to drugs, depression, and seeking excitement. The items in the second factor (passive potential) are largely related to a lack of expressing drug abuse and depression. Based on Cronbach's alpha test, the reliability of the scale was analyzed (0.90) and showed a desirable level.

Two-Parker's parental bonding questionnaire has a 25item self-report questionnaire, which was used to measure 2 dimensions of care/compassion and parent's over protection from the children's viewpoints. Using this, every subject was asked to recall the first 16 years of his/her life and then each one was asked to rank his/her mother's behavior and attitude during this period. This questionnaire is developed based on dependence theory of John Bulbi and evaluates the youth's perception of parental control and attention. It examines 4 factors in parents, including intimate relationship, trying for dependence, indifference, and encouraging for independence. The questionnaire has been designed on the basis of a four-point Likert scale. Of the 25 items in this questionnaire, 12 items were related to care with a score ranging from 0 to 36 and 13 items were related to extreme support from 0 to 39. Of all, 13 items were scored directly and 12 items were reversely scored. The results of validity and reliability of this questionnaire reported by Parker's et al. (1979) showed internal consistency and split-half reliability of 0.88 , test-retest reliability for care of 0.76 , and over protection score of 0.63. In Iran, the validity of this questionnaire has been confirmed by professors and experts in the field of consultation and psychology (12).

3-Maslakh's academic burnout questionnaire was used to evaluate 3 areas of academic burnout, including school fatigue, school apathy (pessimism), and school inefficiency. The questionnaire has 15 items, which were scored on a 7-point Likert's scale ranging from "never to always". School fatigue has 5 items, "all lessons are boring"; school apathy has 4 items, "I feel that I am not interested in lessons"; and school inefficiency has 6 items, "I feel that I cannot cope with the course problems". Items $1,4,7,10$, 
and 13 are related to the subscale of emotional exhaustion, items $2,5,11$, and 14 are related to the subscale of pessimism (apathy), and items 3, 6, 8, 9,12, and 15 are related to the subscale of school inefficiency. As school efficiency scale (i.e. positive statements) is used for this subscale, the items of this subscale are reversely scored.

In Iran, this questionnaire was translated by Sheikh Shabani et al. (2013), and the results indicated a good level of validity and reliability $(13,14)$. Moreover, Sepehri Shamloo et al. evaluated the item total correlation and internal consistency (total alpha), which was $0.79,0.85$, and 0.87 , respectively. The interclass correlation coefficient was 0.87 , indicating a good test-retest reliability $(\mathrm{r}=0.87, \mathrm{P}<0.01)$ (15).

\subsection{Statistical Analysis}

All the collected data were analyzed via SPSS-19. Pearson correlation test was used to examine the relationship between the studied variables. In addition, simultaneous multivariate regression was used to predict addiction potential and to analyze the relationship between parental bonding and addiction potential.

\section{Results}

In this study, there were 300 participants and $85 \%$ (245 people) responded to the questionnaire. Of all, 82 cases (33.5\%) were male and 163 cases (66.5\%) were female. The age mean and the point average was 20.34 years and 16.21, respectively. Forty percent of fathers and $23.3 \%$ of mothers were educated above high school diploma. Whereas point average of $57.6 \%$ of the students was more than 16 .

Table 1 presents the mean and standard deviation of scores obtained from addiction potential, academicburnout, and parental child bonding. The correlations between these scores are presented in Table 2, which indicate a significant correlation between the 6 variables.

Table 3 presents the marginal association between each characteristic of interest and addiction potential scale using one-way analysis of variance (ANOVA). Male gender, higher grade point average, greater academic burnout and care by parents and less care by fathers was associated with greater addiction potential among the students.

Table 4 presents the results of multiple regression models and shows the relationships between each of the explanatory underlying variables related to addiction potential. As shown in Table 4, after adjustment, male gender, higher grade point average, greater academic-burnout and care by both parents, and less control by fathers were associated with increased susceptibility of students to addiction.

\section{Discussion}

The aim of this study was to evaluate parental bonding and academic burnout and their relationship with addiction potential among students. The results showed that parental care, support in general, and also care and support by mother and father separately were predictors of addiction potential. Accordingly, extreme care of the child along with inadequate support is associated with increased addiction potential among students. The experts in the field of social control theory believe that family is very important in the process of socialization of young people; and living with parents cannot protect youth against drug abuse, and there are more important factors, such as parental indifference or family ties with insufficient control, that play a greater role (16). Therefore, parental indifference and lack of control over the child has a strong protective role in connection with the child's tendency to drug abuse (17).

The evaluation of parental role showed that the father's indifference had a significant positive relationship with the children's addiction potential (18). Minuchin, as one of the theorists of structural family therapy, emphasizes the importance of maintaining the hierarchy of power in the family; according to Minuchin's theory, the switch in the role and inadequate power of parents, especially father, is one of the problems in unorganized families (19). Given the family structure in Iran, fathers work outside more than mothers thus they have less supervision over the family. In the Iranian community, fathers usually play their parental supportive role through financing family expenditures. Thus, the overall full supports for the entire family are neglected. In the Iranian family system, if the father does not have any overall supportive role, the family members rely more on other people outside the family, which make them vulnerable (20).

In addition, parenting style is also considered as a predictor of future academic performance and behavioral problems, including addiction in the future (21).

Addiction is a common problem for many families and it is more prevalent among youth at schools and universities. In this study, the researchers observed a positive correlation between high academic burnout and addiction potential.

The results of a study by Abbasi Ghahramanloo et al. (2016) indicated that there was a relatively high prevalence of hookah smoking among Iranian students. Their findings emphasize on planning preventive interventions by considering high-risk behaviors (22). In order to explain their relationship, Dyrbye and colleagues believed that burnout seems to be common among US medical students and may be increased as students proceed in their 
Table 1. Descriptive Indicators of Addiction Potential, Academic Burnout and Parental Bonding $(n=245)$

\begin{tabular}{|c|c|c|c|c|}
\hline Indicators & Variables & Mean \pm SD & Lower & Upper \\
\hline Addiction potential & & $79.03 \pm$ & 77.37 & 80.69 \\
\hline \multirow{6}{*}{ Parental bonding } & Father's care & $28.12 \pm$ & 27.33 & 28.91 \\
\hline & Mother's care & $30.63 \pm 2.53$ & 30.31 & 30.95 \\
\hline & Father's control & $13.01 \pm 5.79$ & 12.28 & 13.74 \\
\hline & Mother's control & $14.09 \pm 6.51$ & 13.27 & 14.91 \\
\hline & Emotional exhaustion & $14.81 \pm 9.13$ & 13.67 & 15.95 \\
\hline & Cynicism & $3.59 \pm 3.23$ & 3.19 & 3.99 \\
\hline \multirow{2}{*}{ Academic-burnout } & School inefficiency & $13.60 \pm 6.48$ & 12.79 & 14.41 \\
\hline & academic -burnout & $32.02 \pm 15.84$ & 30.04 & 34.00 \\
\hline
\end{tabular}

Table 2. Correlation Matrix of Parental Bonding, Academic-Burnout, and Addiction Potential Scale ${ }^{a}$

\begin{tabular}{|c|c|c|c|c|c|c|}
\hline Variables & Addiction Potential & Academic-Burnout & Father's Care & Mother's Care & Father's Control & Mather's Control \\
\hline Addiction potential & 1 & $-0.421(0.001)$ & $0.37(0.001)$ & $0.38(0.001)$ & $-0.3(0.001)$ & $-0.24(0.001)$ \\
\hline academic-burnout & $-0.421(0.001)$ & 1 & $-0.24(0.001)$ & $-0.21(0.001)$ & $0.08(0.166)$ & $0.14(0.023)$ \\
\hline Father's care & $0.37(0.001)$ & $-0.24(0.001)$ & 1 & $0.39(0.001)$ & $-0.33(0.001)$ & $-0.26(0.001)$ \\
\hline Mother's care & $0.39(0.001)$ & $-0.21(0.001)$ & $-0.26(0.001)$ & 1 & $-0.28(0.001)$ & $-0.41(0.001)$ \\
\hline Father's control & $-0.34(0.001)$ & $0.08(0.166)$ & $-0.33(0.001)$ & $-0.28(0.001)$ & 1 & $0.55(0.001)$ \\
\hline Mother's control & $-0.24(<0.001)$ & $0.14(0.023)$ & $-0.26(<0.001)$ & $-0.41(<0.001)$ & $0.55(<0.001)$ & 1 \\
\hline
\end{tabular}

${ }^{\mathrm{a}}$ Values are expressed as $\mathrm{r}$ (P value).

course. Despite the notion that burnout is primarily linked to work-related stress, personal life events also indicate a strong relationship with professional burnout (23). On the other hand, the researchers observed a positive relationship between this strategy and drug abuse (24). In other words, it can also be said that the use of emotional and avoidant coping strategies to control stress involving emotional focus on issues and avoiding or denying the issue is associated with both academic burnout and addiction potential. Thus, training to use problem-based coping strategies helps reduce burnout and addiction potential. Finally, it can be concluded that, as addiction potential and academic burnout are associated with parenting style, training and correcting parenting practices reduce addiction potential and academic burnout; it can also help children use correct strategies to cope with stress and solve problems.

The finding of Guo et al.'s study (2016) showed a significant relationship between progress in education and the probability of being a smoker. In other words, having poor progress in education along with low grades in terms of score average is associated with increased probability of drug abuse (25). In the recent years, using drugs and psy- chotropic substances, which are commonly used as reinforcement in educational performance among university students, have increased; and the current findings confirm this claim (26).

The results showed that addiction potential is stronger in male students than in females. The two genders vary greatly in terms of biological and hormonal factors; on the other hand, due to the presence of testosterone among males, they may show more aggressive behaviors, which have a significant positive relationship with higher level of addiction potential. In addition, since family supervision over males is less than females, thus in case of mental and psychological crisis, females suffer more from depression and anxiety whereas males turn to drugs (27). Considering the expectations towards females' addiction in the community, drug abuse behaviors among females is less than in males, so this attitude reduces the females' tendency to addiction (28).

\subsection{Conclusions}

Numerous factors, such as male gender, higher grade point average, more academic burnout, more care by parents or less control by father are associated with increased 
Table 3. Marginal Association Between Each Characteristic of Interest and Addiction Potential Scale Using One-Way Analysis of Variance

\begin{tabular}{|c|c|c|c|c|c|c|}
\hline $\begin{array}{l}\text { Addiction Potential } \\
\text { Scale }\end{array}$ & & Sum of Squares & Degree of Freedom & Mean of Squares & $\mathbf{F}$ & P Value \\
\hline \multirow{2}{*}{ Gender } & Between Groups & 1113.53 & 1 & 1113.53 & \multirow{2}{*}{6.43} & \multirow{2}{*}{0.012} \\
\hline & Within Groups & 42029.36 & 243 & 172.96 & & \\
\hline \multirow{2}{*}{ Age } & Between Groups & 50.214 & 1 & 50.21 & \multirow{2}{*}{0.28} & \multirow{2}{*}{0.592} \\
\hline & Within Groups & 41358.16 & 237 & 174.50 & & \\
\hline \multirow{2}{*}{ Family size } & Between Groups & 22.79 & 1 & 22.79 & \multirow{2}{*}{0.12} & \multirow{2}{*}{0.720} \\
\hline & Within Groups & 43120.10 & 243 & 177.44 & & \\
\hline \multirow{2}{*}{ Course of study } & Between Groups & 1.96 & 1 & 1.96 & \multirow{2}{*}{0.01} & \multirow{2}{*}{0.916} \\
\hline & Within Groups & 43140.93 & 243 & 177.53 & & \\
\hline \multirow{2}{*}{ Average grade } & Between Groups & 1049.09 & 1 & 1049.09 & \multirow{2}{*}{6.05} & \multirow{2}{*}{0.015} \\
\hline & Within Groups & 42093.80 & 243 & 173.22 & & \\
\hline \multirow{2}{*}{ Parents education } & Between Groups & 35.92 & 1 & 35.92 & \multirow{2}{*}{0.20} & \multirow{2}{*}{0.653} \\
\hline & Within Groups & 43106.97 & 243 & 177.39 & & \\
\hline \multirow{2}{*}{ Academic-burnout } & Between Groups & 4227.93 & 1 & 4227.93 & \multirow{2}{*}{26.40} & \multirow{2}{*}{$<0.001$} \\
\hline & Within Groups & 38914.96 & 243 & 160.14 & & \\
\hline \multirow{2}{*}{ Father's care } & Between Groups & 4131.83 & 1 & 4131.83 & \multirow{2}{*}{25.73} & \multirow{2}{*}{$<0.001$} \\
\hline & Within Groups & 39011.06 & 243 & 160.53 & & \\
\hline \multirow{2}{*}{ Mother's care } & Between Groups & 4634.84 & 1 & 4634.84 & \multirow{2}{*}{29.24} & \multirow{2}{*}{$<0.001$} \\
\hline & Within Groups & 38508.05 & 243 & 158.46 & & \\
\hline \multirow{2}{*}{ Father's control } & Between Groups & 2186.91 & 1 & 2186.91 & \multirow{2}{*}{12.97} & \multirow{2}{*}{$<0.001$} \\
\hline & Within Groups & 40955.98 & 243 & 168.54 & & \\
\hline \multirow{2}{*}{ Mother's control } & Between Groups & 1979.34 & 1 & 1979.34 & \multirow{2}{*}{11.68} & \multirow{2}{*}{0.001} \\
\hline & Within Groups & 41163.55 & 243 & 169.39 & & \\
\hline
\end{tabular}

Table 4. The Relationships Between the Remaining Variables Related to Addiction Potential Based on Final Reduced Multiple Regression Models

\begin{tabular}{|c|c|c|c|c|}
\hline Variable & B & Std. Error & $\mathbf{t}$ & P Value \\
\hline Male gender & 6.718 & 1.613 & 4.166 & $<0.001$ \\
\hline Average grade & 3.556 & 1.522 & 2.337 & 0.020 \\
\hline Academic-burnout & 6.460 & 1.487 & 4.345 & $<0.001$ \\
\hline Father's care & 6.503 & 1.812 & 3.589 & $<0.001$ \\
\hline Father's control & -4.058 & 1.502 & -2.702 & 0.007 \\
\hline
\end{tabular}

susceptibility of students to addiction. Also, the campus of the university and student rooms could be a potential place to develop addiction.

By studying the risk factors obtained from this study, the authors conclude that this group needs enough attention and emotional support on the behalf of family and university. By developing mental health centers and counseling with students, preventive measures could be taken even for those, who are amusing drug abusers.

The limitation of the study was the lack of cooperation in the questionnaire by some students, however, it was compensated by increasing the sample size. 


\section{Acknowledgments}

This paper was extracted from a research project sponsored by the Student Research Committee of Semnan University of Medical Sciences. Also, the authors would like to appreciate all employees, teachers, and students of Semnan University of Medical Sciences, who helped with this study, especially, Hamed Nikpourian and Ebrahim Badavi, and students of MD for gathering the data.

\section{Footnote}

Authors' Contribution: Mohammad Amin Vafae, Mohammadreza Moonesan, and Mojtaba Soltani collected the data. Abbas Ziari and Majid Mirmohammadkhani designed the study and analyzed the data and Masoudeh Babakhanian prepared the manuscript. All authors studied and approved the final manuscript.

\section{References}

1. Khalsa JH, Treisman G, McCance-Katz E, Tedaldi E. Medical consequences of drug abuse and co-occurring infections: research at the National Institute on Drug Abuse. Subst Abus. 2008;29(3):5-16. doi: 10.1080/08897070802218661. [PubMed: 19042203].

2. Munoz-Laboy M, Martinez O, Guilamo-Ramos V, Draine J, Garg KE, Levine E, et al. Influences of Economic, Social and Cultural Marginalization on the Association Between Alcohol Use and Sexual Risk Among Formerly Incarcerated Latino Men.J Immigr Minor Health. 2017 doi: 10.1007/s10903-017-0554-z. [PubMed: 28197862].

3. De Ridder D, Vanneste S, Gillett G, Manning P, Glue P, Langguth B. Psychosurgery Reduces Uncertainty and Increases Free Will? A Review. Neuromodulation. 2016;19(3):239-48. doi: 10.1111/ner.12405. [PubMed: 26899938].

4. Nakhaee N, Ziaaddini H, Karimzadeh A. Epidemiologic Study on Drug Abuse among First and Second Grade High School Students in Kerman. Addict Health. 2009;1(1):31-6. [PubMed: 24494080].

5. Geramian N, Akhavan S, Gharaat L, Tehrani AM, Farajzadegan Z. Determinants of drug abuse in high school students and their related knowledge and attitude. J Pak Med Assoc. 2012;62(3 Suppl 2):S62-6. [PubMed: 22768463].

6. Aquilino WS, Supple AJ. Long-Term Effects of Parenting Practices During Adolescence on Well-Being Outcomes in Young Adulthood.J Fam Issues. 2016;22(3):289-308. doi: 10.1177/019251301022003002.

7. Gil AG, Vega WA, Biafora F. Temporal influences of family structure and family risk factors on drug use initiation in a multiethnic sample of adolescent boys. J Youth Adolescence. 1998;27(3):373-93. doi: 10.1023/a:1022807221074.

8. Benjet C, Borges G, Mendez E, Casanova L, Medina-Mora ME. Adolescent alcohol use and alcohol use disorders in Mexico City. Drug Alcohol Depend. 2014;136:43-50. doi: 10.1016/j.drugalcdep.2013.12.006. [PubMed: 24438842].

9. Lamborn SD, Mounts NS, Steinberg L, Dornbusch SM. Patterns of competence and adjustment among adolescents from authoritative, authoritarian, indulgent, and neglectful families. Child Dev. 1991;62(5):1049-65. [PubMed: 1756655].

10. Weed NC, Butcher JN, McKenna T, Ben-Porath YS. New measures for assessing alcohol and drug abuse with the MMPI-2: The APS and AAS. J Pers Assess. 1992;58(2):389-404. doi: 10.1207/s15327752jpa5802_15. [PubMed: 1315859].
11. Zargar Y, Najjarian B, Naami A. Relationship Personality characteristics (sensation seeking, assertiveness, perseverance Psychological), religious attitude and marital satisfaction with the readiness to Drug addiction. J Educ. 2008;1(3):99-120.

12. Behzadi B, Parker G. A Persian version of the parental bonding instrument: factor structure and psychometric properties. Psychiatry Res. 2015;225(3):580-7. doi: 10.1016/j.psychres.2014.11.042. [PubMed: 25530418].

13. Schaufeli WB, Salanova M, Gonzalez-roma V, Bakker AB. The measurement of engagement and burnout: A two sample confirmatory factor analytic approach. J Happiness Stud. 2002;3(1):71-92. doi: 10.1023/a:1015630930326.

14. Sheikh Shabani E, Bazrafkan H, Azizi M. The factor analyze of academic burnout Maslakh in girl student. Qj Womens Stud Sociol Psychol. 2013;11(1):175-204.

15. Sepehri Shamloo Z, Hashemian SS, Khoshsima H, Shahverdi A, Khodadost M, Modares Gharavi M. Validity and Reliability of the Persian Version of the Maslach Burnout Inventory (General Survey Version) in Iranian Population. Iran J Psychiatr Behav Sci. 2017;In Press(In Press) doi: $10.5812 /$ ijpbs.8168.

16. Balazs MA, Piko BF, Fitzpatrick KM. Youth Problem Drinking: The Role of Parental and Familial Relationships. Subst Use Misuse. 2017;52(12):1538-45. doi: 10.1080/10826084.2017.1281311. [PubMed: 28406347].

17. Fulkerson JA, Pasch KE, Perry CL, Komro K. Relationships between alcohol-related informal social control, parental monitoring and adolescent problem behaviors among racially diverse urban youth. $J$ Community Health. 2008;33(6):425-33. doi: 10.1007/s10900-008-9117-5. [PubMed: 18607698].

18. Jones JD, Ehrlich KB, Lejuez CW, Cassidy J. Parental knowledge of adolescent activities: links with parental attachment style and adolescent substance use. J Fam Psychol. 2015;29(2):191-200. doi: 10.1037/fam0000070. [PubMed: 25730406].

19. Berzonsky MD. In: Advances in Personal Construct Psychology. Neimeyer GJ, Neimeyer RA, editors. ; 1990. pp. 155-86.Selfconstruction over the Life-span: A Process Perspective on Identity Formation.

20. Zeinali A, Vahdat R, Garadingeh K. The Relationship Between Parenting Style and Addiction Susceptibility in Children. J Fam Res. 2010;6(3):335-52.

21. Qiang C, Xing Q, Huimin LU, Pei FEI, Ming LI. Comparison of the personality and other psychological factors of students with internet addiction who do and do not have associated social dysfunction. Shanghai Arch Psychiatr. 2015;27(1):36.

22. Abbasi-Ghahramanloo A, Fotouhi A, Zeraati H, Rahimi-Movaghar A Prescription drugs, alcohol, and illicit substance use and their correlations among medical sciences students in iran. Int J High Risk Behav Addict. 2015;4(1):e21945. doi: 10.5812/ijhrba.21945. [PubMed: 25821750].

23. Dyrbye LN, Thomas MR, Huntington JL, Lawson KL, Novotny PJ, Sloan JA, et al. Personal life events and medical student burnout: a multicenter study. Acad Med. 2006;81(4):374-84. [PubMed: 16565189].

24. Melchior M, Chastang JF, Goldberg P, Fombonne E. High prevalence rates of tobacco, alcohol and drug use in adolescents and young adults in France: results from the GAZEL Youth study. Addict Behav. 2008;33(1):122-33. doi: 10.1016/j.addbeh.2007.09.009. [PubMed: 17919830].

25. Guo L, Deng J, He Y, Deng X, Huang J, Huang G, et al. Alcohol use and alcohol-related problems among adolescents in China: A largescale cross-sectional study. Medicine (Baltimore). 2016;95(38):e4533. doi: 10.1097/MD.0000000000004533. [PubMed: 27661013].

26. Herman L, Shtayermman O, Aksnes B, Anzalone M, Cormerais A, Liodice $C$. The use of prescription stimulants to enhance academic performance among college students in health care programs.JPhysician Assist Educ. 2011;22(4):15-22. [PubMed: 22308929]. 
27. Haberthur AK, Elkuch FM, Grosse Holtforth M, Hochstrasser B, Soyka M. Characterization of patients discharged from inpatient treatment for burnout: use of psychological characteristics to identify aftercare needs. J Clin Psychol. 2009;65(10):1039-55. doi: 10.1002/jclp.20606.
28. Babakhanian M, Mansouri S, Moradi Z, Abarashi Z. High purity heroin use among women in karaj, iran: a pilot study. Iran J Psychiatry Behav Sci. 2013;7(2):51-6. [PubMed: 24644510]. 